\title{
Brain infarction associate with a mobile thrombus in the aortic arch at the previous site of the ductus arteriosus
}

Hikaru Ishii, MD, Hidehito Endo, MD, and Hiroshi Kubota, MD, Tokyo, Japan

From the Department of Cardiovascular Surgery, Kyorin University, Tokyo, Japan.

Disclosures: Authors have nothing to disclose with regard to commercial support.

Received for publication Oct 15, 2016; revisions received Jan 4, 2017; accepted for publication Jan 18, 2017; available ahead of print March 1, 2017.

Address for reprints: Hikaru Ishii, MD, Department of Cardiovascular Surgery, Kyorin University, 6-20-2 Shin-

kawa, Mitaka-shi, Tokyo 181-8611, Japan (E-mail: hikaru3@dg8.so-net.ne.jp).

J Thorac Cardiovasc Surg 2017; 154:e1-3

$0022-5223 / \$ 36.00$

Copyright (c) 2017 by The American Association for Thoracic Surgery

http://dx.doi.org/10.1016/j.jtcvs.2017.01.007

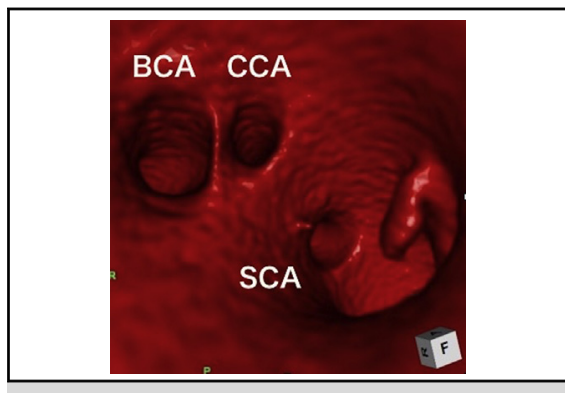

Computed tomography image showing a mobile thrombus on the ligamentum arteriosum in the aortic arch.

\section{Central Message}

Patients with idiopathic cerebral infarction and acute anemia should be regarded as having cerebral infraction of aortic origin.

See Editorial Commentary page e5.

Arteriosclerotic change in the underside of the arch at the previous insertion site of the ductus arteriosum (UDA) and acute anemia may accelerate thrombus formation at

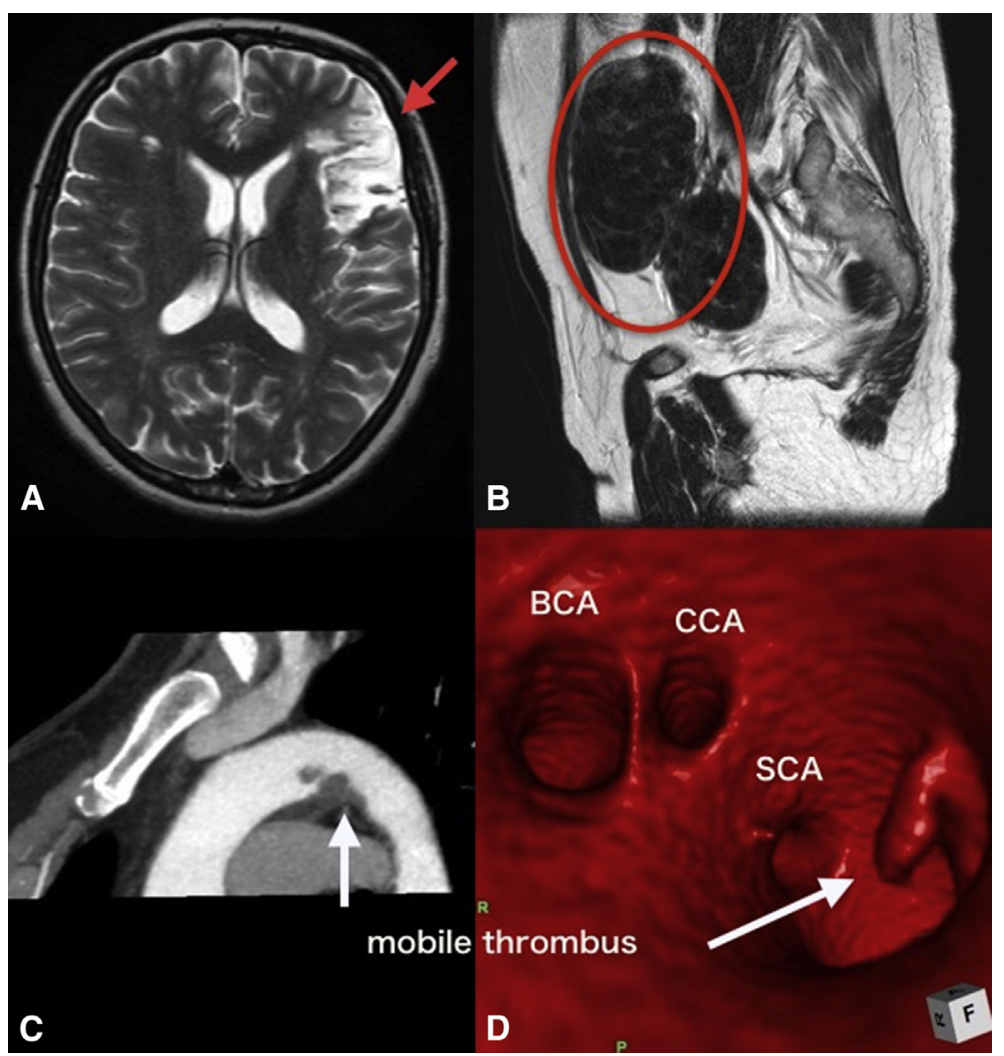

FIGURE 1. A (arrow), Head magnetic resonance imaging showing a large left-sided brain infarction. B (circle), Magnetic resonance imaging showing uterine fibroids and an endometrial cyst. $\mathrm{C}$ and $\mathrm{D}$ (arrows), Whole-body computed tomography demonstrating a mobile thrombus in the aortic arch. $B C A$, Brachiocephalic artery; $C C A$, common carotid artery; $S C A$, subclavian artery. 


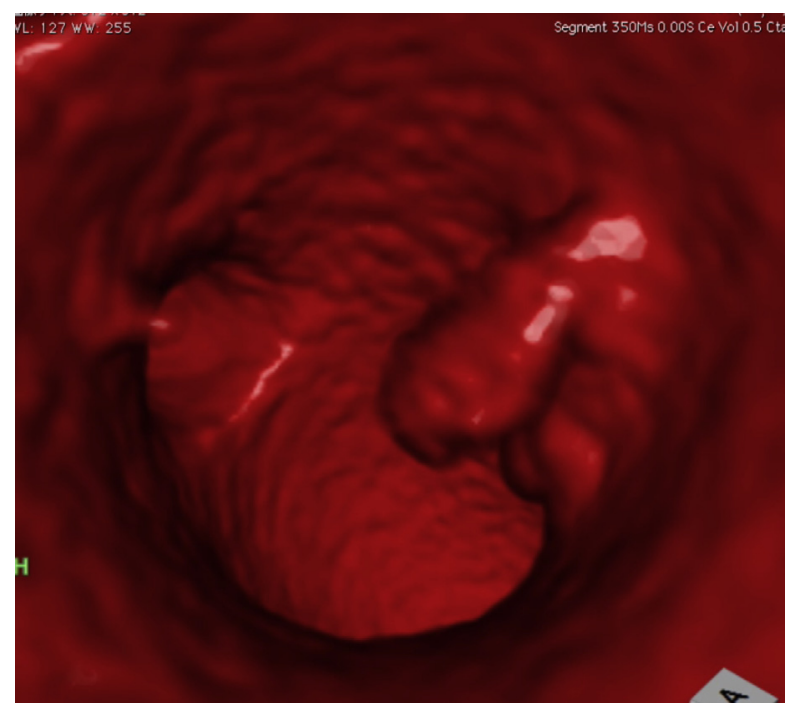

VIDEO 1. Whole-body computed tomography demonstrating a mobile thrombus in the aortic arch. Video available at: http://www.jtcvsonline. org/article/S0022-5223(17)30124-1/addons.

this site and can be a potential source of brain infarction, even in the young.

A large mobile thrombus in the aortic arch, without bulky atheromatous disease, is an unusual finding. A 41-year-old woman without a history of affective disorder was admitted to Kyorin University because of sudden

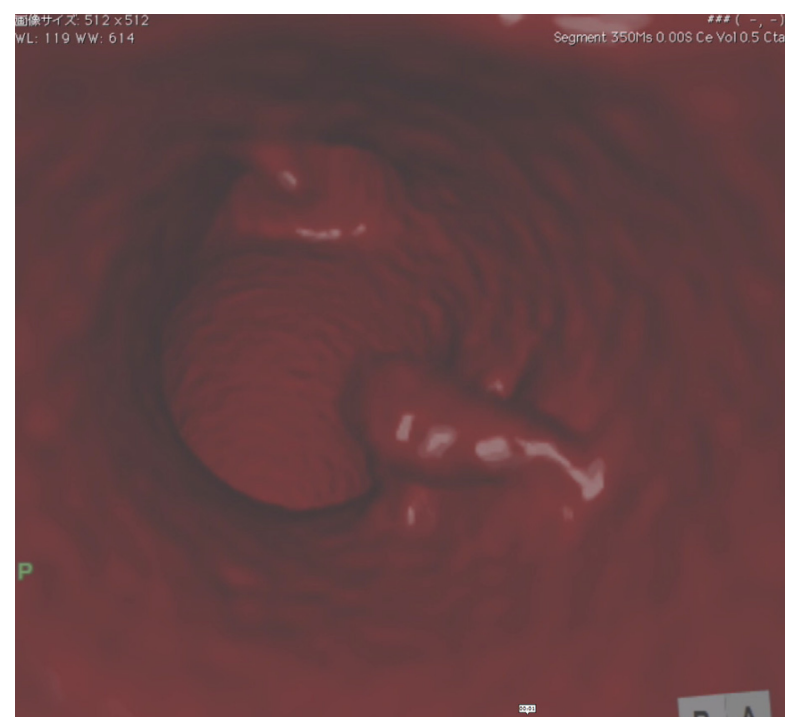

VIDEO 2. Whole-body computed tomography demonstrating a mobile thrombus in the aortic arch. Video available at: http://www.jtcvsonline. org/article/S0022-5223(17)30124-1/addons.

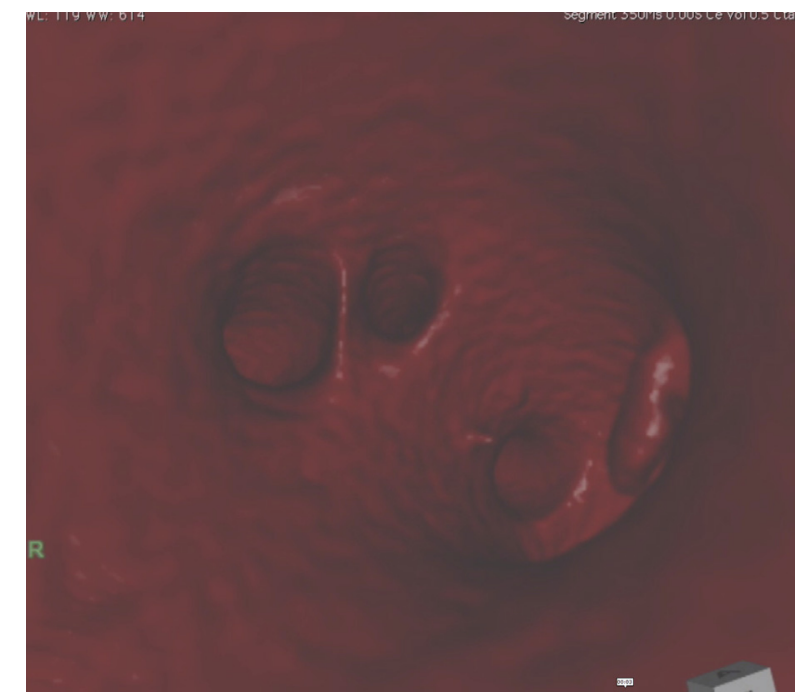

VIDEO 3. Whole-body computed tomography showing the location of the mobile thrombus. Video available at: http://www.jtcvsonline.org/article/ S0022-5223(17)30124-1/addons.

motor aphasia and amnesia. Laboratory analysis revealed severe anemia with a hemoglobin level of $7.5 \mathrm{~g} / \mathrm{dL} ; 2$ years previously, this was $11.5 \mathrm{~g} / \mathrm{dL}$. Head magnetic resonance imaging revealed a large left-sided brain infarction (Figure 1, A). Whole-body magnetic resonance imaging revealed uterine fibroids and endometrial cysts (Figure 1, $B)$. Abnormalities were not noted on electrocardiography, echocardiography, and carotid echocardiography. Chest computed tomography revealed a mobile thrombus in the UDA (Figure 1, $D$ and $E$, and Videos 1-3). A total arch replacement was performed. ${ }^{1}$ The histopathologic finding of the aortic wall was normal except for arteriosclerotic change in a part of the UDA. The thrombus adhered to this part (Figure 2).

Calcification of the UDA on a chest radiograph appears from a few months to several years after closure of the ductus arteriosus. ${ }^{2}$ Ampanozi and colleagues ${ }^{3}$ reported that calcification of the UDA is a common finding in adults and increases in prevalence with increasing age and atherosclerosis. Thus, the degree of calcification and atherosclerosis of the UDA is considerably higher than that of other parts of the aorta. Therefore, arteriosclerotic change of the UDA is a potential source of embolic stroke even in the young.

Acute anemia can accelerate thrombus formation in the aortic arch. Bukharovich ${ }^{4}$ reported arterial embolism associated with iron-deficiency anemia.

Our case has shown that arteriosclerotic change in the UDA and acute anemia may cause embolic stroke, even in the young. 


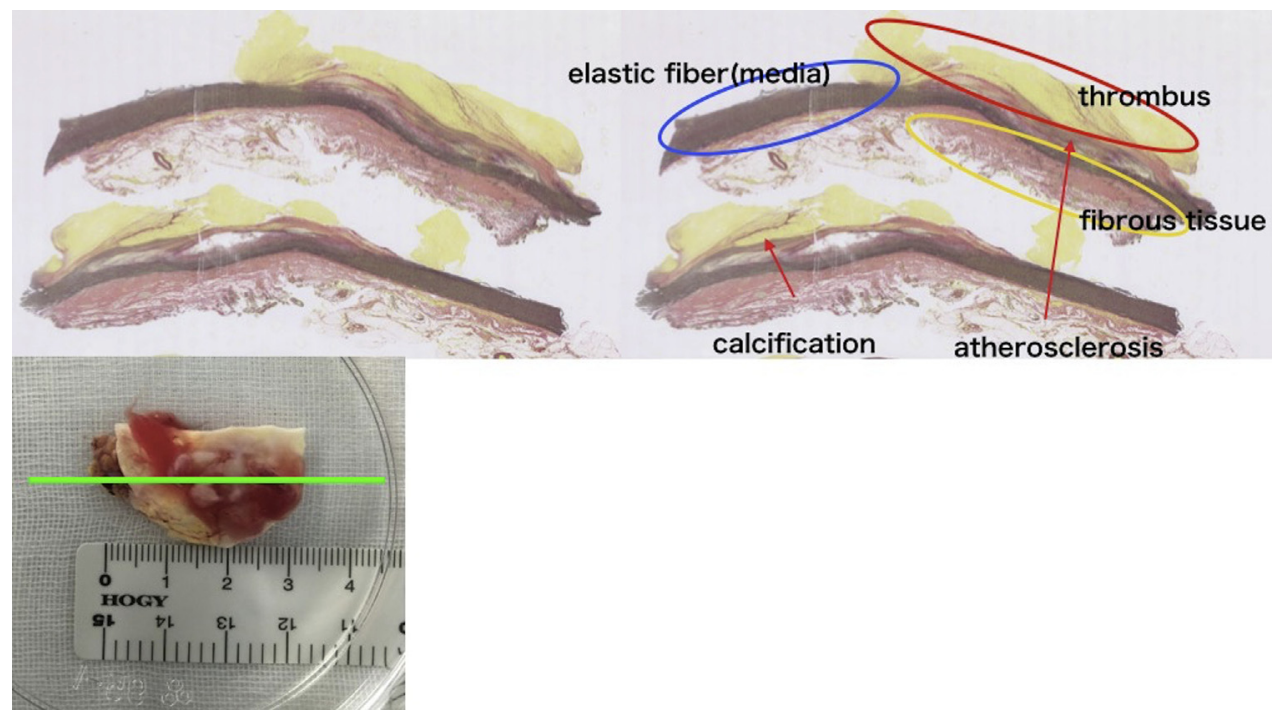

FIGURE 2. Histopathologic findings of the aortic wall were normal except for the ligamentum arteriosum with arteriosclerotic change. A mobile thrombus adhered to the aortic wall, which was a part of the ligamentum arteriosum.

\section{References}

1. Endo H, Ishii H, Tsuchiya H, Takahashi Y, Inaba Y, Nishino Y, et al. Observations of retinal vessels during intermittent pressure-augmented retrograde cerebral perfusion in clinical cases. Interact Cardiovasc Thorac Surg. 2016;23:259-65.

2. Hong GS, Goo HW, Song JW. Prevalence of ligamentum arteriosum calcification on multi-section spiral CT and digital radiography. Int J Cardiovasc Imaging. 2012;28(Suppl 1):61-7.
3. Ampanozi G, Ruder TD, Hatch GM, Bolliger S, Thali MJ. Incidental findings in post-mortem CT: calcified ligamentum arteriosum. Leg Med. 2010;12: 313-5.

4. Bukharovich IF. Arterial embolism caused by large mobile aortic thrombus in the absence of atherosclerosis, associated with iron deficiency anemia. Echocardiography. 2012;29:369-72. 